\title{
Imagining multicultural London: containment and excess in snatch
}

Article

Accepted Version

Garfield, R. (2014) Imagining multicultural London:

containment and excess in snatch. European Judaism, 47 (2). pp. 60-68. ISSN 0014-3006 doi:

https://doi.org/10.3167/ej.2014.47.02.08 (Special issue

"Writing Jews In Contemporary Britain") Available at https://centaur.reading.ac.uk/38415/

It is advisable to refer to the publisher's version if you intend to cite from the work. See Guidance on citing.

Published version at: http://dx.doi.org/10.3167/ej.2014.47.02.08

To link to this article DOI: http://dx.doi.org/10.3167/ej.2014.47.02.08

Publisher: Berghahn Journals

All outputs in CentAUR are protected by Intellectual Property Rights law, including copyright law. Copyright and IPR is retained by the creators or other copyright holders. Terms and conditions for use of this material are defined in the End User Agreement.

\section{www.reading.ac.uk/centaur}

\section{CentAUR}

Central Archive at the University of Reading 
Reading's research outputs online 
"Imagining Multicultural London: Containment and Excess in Snatch",European Judaism, Vol

47, No. 2, Autumn 2014, eds. Sue Vice \& Axel Staehler, pp 60-68, Berghahn Journals

\title{
IMAGINING MULTICULTURAL LONDON: CONTAINMENT AND \\ EXCESS IN SNATCH Rachel Garfield
}

\begin{abstract}
Snatch (Guy Ritchie, 2000) is a comic-book gangster film that can be seen to represent the backlash against perceived notions of political correctness in what is effectively a public-schoolboy fantasy of working-class life in East London. However, the film also delineates the limits of this backlash in its depiction of minorities as either contained or excessive. This is highlighted through the comic-book genre itself as well as the characterization. Thus this article explores the tension between the genre, representation and Jewish identity.

$</ \mathbf{E X T}>$
\end{abstract}

Snatch is about a heist. It is a comic-book film that revolves around a diamond that is stolen in Amsterdam and taken to London. It interweaves another plot, set in London, about an unregulated boxing match, narrated by the boxing manager. When the two worlds collide the film begins. Structurally the film is made up of vignettes, fragmented across space and time following a certain type of action-based comicbook style, that of the superhero, although no one here is exactly a hero.

Guy Ritchie, at the time famously the husband of Madonna, directed the film, which stars Brad Pitt, Benicio del Toro and Dennis Farina. This was Ritchie's second feature film and was given a major release in 2000. It will be argued in this article that the film Snatch represents, through its depictions, a multiculturalism that is conceived 
as a backlash against what is thought of as political correctness in the public-school fantasy of Ritchie's gangsters' London. Within this context Jewishness is not only included, and unusually so within the genre in Britain, but amplified through the representation of an ersatz version of itself: in several instances, some characters either pretend to be Jewish or use Jewishness as a camouflage. This range of depictions can give useful insights into the representation of Jewishness and what is at stake more generally within the text.

The film is a shaggy-dog story that takes place over the period of a week. The diamond is stolen once and then stolen again, recovered, lost and recovered again. The boxing match has a similar trajectory, since the boxer is replaced by another character and then fights for too long, not doing what he is told (he has to go down in the fourth round - and never does) and fighting again. Both the diamond heist and the boxing match are merely vehicles for the romp, and narrative progression is replaced by repetition.

If the gangster film is considered as a genre that allows the viewer to feel liberated from all social mores and constraints through the characterization of the subjects, this film accomplishes that through the narrative, ${ }^{1}$ but, unlike other key films in the genre that will serve as comparison, such as Mean Streets (1973), The Godfather (1972) or Once Upon a Time in America (1984), Snatch frees the viewer from any sense of past, geographical specificity or familial ties. Although set in London, there are no establishing shots that would depict any specific location: the ties, as constructed by the film, are thus to the life the characters lead and not to any specific place. The locations that exist, in London, New York and Amsterdam, are indicated through intertitles, as is usual for the genre, but these locations are either shot as interiors or are so tightly framed as to preclude any urban specificity: these 
cities could be almost anywhere, and could indicate not only a kind of global cosmopolitanism of diasporic communities, but also a narrative based on class rather than geographical specificity. Thus shifts in geography and chronology are just an edit away, borrowing from comic-book visual constructions, in the way that the story is told through split-screen devices, off-the-shelf symbolism and parallel editing. For example, in one scene where Doug the Head and Abraham 'Avi' Denovitz are talking on the phone, the screen is split, showing just two pairs of feet crossed and resting on a fireplace. On one side Doug the Head is wearing Union Jack socks and on the other, Avi has a copy of the Jewish News nestling next to his feet. These visual signs are as powerful, but also as one-dimensional, as the protagonists' comic-book names: 'Doug the Head', 'Franky Four Fingers', 'Boris the Blade'. Each is introduced with a comicbook still and a description. ${ }^{2}$

The camera only films what is necessary for the unfolding of events, so for example there is no evolution of character motivation through the film, nor reflection on them beyond the story itself, and no characterization of the main protagonists other than a merely functionalist one, offered by the narrator. For instance, the viewer learns that Boris the Blade is 'bent as a soviet sickle and hard as the hammer that crosses it. Apparently it is impossible to kill the bastard', while of Bricktop we learn that 'it's rumoured that Bricktop's favourite role of dispatch is a stun gun, a plastic bag, a roll of tape and a pack of hungry pigs'. The simplicity is not minimalist or stylish but merely one-dimensional, in a way that lends a bathetic quality to the lives of the protagonists, suggesting that everyone is living by the skin of their teeth. The music is light-hearted at the most brutal moments in a way that heightens the desperate quality of the brutality while distancing the viewer at the same time. All these devices, including the fast pace of events, the music, the nicknames 
and the mise en scène, serve to obviate any empathy with the subjects on screen and relegate them to a comic-book two-dimensionality. This is a crucial feature in relation to the film's portrayal of identity.

The characters are thus symbolic forms with no interiority. If Snatch is compared to earlier gangster movies such as Once Upon a Time in America, it is clear that the portrayal of events in the latter was a humanist one that focused on the characters and aimed to understand their motivations as well as their journey from innocence to becoming deeply embroiled in moral ambivalence. Such films often represent a lost world and an innocence that cannot be regained. The question about how one becomes a gangster was tied in some ways to notions of assimilation and what it cost to build a life in the USA for ethnic minority communities. It was part of the self-representation of the USA that was sold back to itself. The Godfather told the story of the stereotypical familial ties and loyalties that pulled the reluctant younger son into the fold of the family to become the Godfather himself, reinforcing the power of the familial firm. Even Mean Streets, which shares some of the conceits of Snatch, offers a more complex cinematic reality through the camerawork. Like Snatch, it does not aim for an epic trajectory, is set in the present and focuses on a small group of young men. However, in the earlier film the camerawork aims to give a sense of the interior struggles and decisions that drive the future lives of the protagonists. Moreover, in Mean Streets the sense of place and what it stands for in relation to community is crucial to the idea of identity and central to the film's narrative. ${ }^{3}$ Yet Snatch follows neither the visceral grittiness alongside British lack of attention to ethnic identifications, nor the theatricality and despair of some other British films such as The Essex Boys (2000) or The Rise of the Footsoldier (2007). ${ }^{4}$

If a comparison is to be made, Snatch is more akin to Reservoir Dogs (Quentin 
Tarantino, () in the sense that it portrays another myth: that of a deracinated pick-andmix urban culture where everyone is for themselves. In its ethnic imagination, Ritchie brings to this film of British gangsterism the over-determination of race and ethnicity more usual to a US sensibility but with a particularly British preoccupation, through the focus on the Irish Traveller community.

In some ways a comparison between the US and the UK in relation to this film is flawed. The concern with origin and provenance in representation is not the same, due to the different historic contexts and narratives. The UK's narrative is not so much one of the American melting pot but one of postcolonial immigration and assimilation. London's East End has a long history of being feared as the place to be attacked, mugged or disturbed by the rabble, and was used extensively as exemplar in the 1902 Royal Commission on Immigration towards the introduction of the first Aliens Act in $1905 .{ }^{5}$ The East End, in the popular imagination, still represents the first port of call for immigrant communities, although for Jews particularly it is now little more than a nostalgic cultural memory. While there are a few pockets of predominantly elderly Jews in Tower Hamlets and three synagogues that struggle to get a minyan on Sabbath, tours of the 'Jewish East End' proliferate. Furthermore, while the community in the borough is diverse, there are many other parts of London (and other parts of the UK, such as Kent) which receive comparatively large numbers of new immigrants.

The story that Ritchie delineates tells of the lowlife of a slightly quaint London, imagined as an ethnic mix that offers a particular frisson of the exotic-even if in comic and deflationary terms - giving flavour to the film. Even the English characters frequently have assumed names with particular ethnic associations. For instance, the protagonist, apparently a native English cockney, is called 'Turkish', 
while others pretend they are of particular origins, such as 'Doug the Head', who claims to be Jewish. The cavalier attention to identity can be seen in the comic-book genre where authenticity is never presumed or expected and is often challenged directly through the ubiquity of disguises. No one is quite what they seem in superhero-land. Violence is quickly forgotten and identity lightly taken. ${ }^{6}$ However, in Snatch there is something more at stake than there is in a classic superhero narrative. This is a postmodern consideration of such hopes and dreams where not much is expected of the protagonists, who are acting as individuals serving their own interests, unlike the classic superheroes such as Superman or Spiderman, who were given the role of saving the planet from evil-doers.

In some ways Snatch seems very Jewish. The long opening shots focus on Jews - although they are fake ones, dressed up as frummers, speaking in stereotypical Yiddish accents about the finer points of Torah (or rather, Christian misreadings of the Torah, such as the mistranslation of 'young woman' into 'virgin') in order to steal the diamond from the diamond dealers. 'Doug the Head' is a pretend-Jewish jeweller who 'Jews up' his accent and wears a black kippah because he thinks it is good for business. The 'street'-speaking, doorstep-loitering, cigarette-smoking frummer boys, who are told to 'fuck off' from his Hatton Garden doorstep by Doug the Head, defy expectation with their un-Yiddish accents and the loitering that confounds the stereotype of the frummers (or the expectations of the audience about who the Jew should be). It seems that the film is thickly scattered with Jews, but there is only one character in the film who actually is Jewish. This is Avi, who is given stereotypical traits, although not caricature dress: he is introduced in his office, tossing a coin in the air and sounding impressed by the carats in the diamond, ordering his guys to get it for him. So this film could be read, in Jewish terms, through the bifurcation of the Jew 
as both utterly assimilable and interchangeable with non-Jews, since it is just a matter of dressing up, and at the same time utterly other.

Stereotype is at the core of this fantasy of multiculturalism where there are many ethnicities swimming in the same underclass soup, each with a specialism of its own. These specialisms are tied to a stereotype - the hard-nut but eccentric Brit, the ruthless Russian arms-trader, the hapless but secretly cunning Irish Traveller who loves his mam more than anything; the three stooges or 'stupid black guys', as wheeler-dealers who always fail. While the original Three Stooges were Jewish, here they are reimagined as black. ${ }^{7}$ This is an inverse of the connection Michael Rogin identifies in Blackface, White Noise, where Jewish, Irish and black individuals are connected through blackface. Rogin argues that in 'blacking up', the Jews and the Irish did not show solidarity with black marginality but conversely used it as a differentiating sign that allowed them to assimilate. In other words, because a black man does not need to black up, a Jew blacking up reinforces his whiteness. ${ }^{8}$ Finally, Avi is the boss and does not get his hands dirty, since he is represented as the Jew at the top of the pile. If anyone does not fit into this schema, it is the Irish Travellers, who are picked as subjects of derision ('I hate Pikeys' is the refrain throughout the film). They are the most othered, not just through explicit name-calling but also through their being depicted as speaking a kind of slurred pidgin gibberish that the English characters can barely understand. They are also the only characters in the film embedded in a community, which implies that to be English you cannot be closely tied to such an entity - the community instead is your individualism.

The extensive use of closed-circuit television (CCTV) in the film further distances the viewer from the protagonists and unwittingly invokes the double consciousness of W. E. B. Du Bois. ${ }^{9}$ For example, the opening shots that depict the 
heist are all seen by the audience through CCTV screens. There is also a moment when Solomon is looked at by the viewer and then, in the following shot, through a CCTV screen behind him. Through the CCTV the images of the Other are decoupled from any subjectivity, essentialized in their image of difference and the character that is tied to it. The implication of authenticity that runs through such narratives as Once Upon a Time in America or The Godfather is of no use here. Snatch speaks instead directly to the debates on tolerance in its picaresque setting out of players; that is, the characters are rendered as impotent signs of otherness, objects of humour and thus safe and contained for the normative viewer.

The use of CCTV importantly foregrounds the lack of class diversity in the characters. There is no one who acts as a counterpoint to the gangsters in the film and in this way it is a multicultural goldfish-bowl where the counterpoint is the director (or the implied middle-class viewer). Thus the characters in the film reflect back to the viewer his (or her) own normativity. In this way the characters are the excess ${ }^{10}$ to the absent WASP, middle- and upper-class gentility, where noblesse oblige rules, and where no one feeds their enemies to pigs.

In The New Jew in Film Nathan Abrams describes the role of the Jew in gangster films:

$<\mathrm{EXT} />$

Many violent films depict Jews who are not only out of their depth, but also ..., metaphorically speaking, cannot swim. Gangster films in particular, present Jews as victims. Typically, the Jew attempts to pass as tough, posturing as a gangster but is ultimately exposed as unable to cut the mustard criminally and ends up dead. Often little sympathy for the plight is demonstrated, as these Jews tend to be ugly, both morally/ethnically and 
physically. ${ }^{11}$

$</$ EXT $>$

This could be a description of Sol, the black pawnbroker, and his two sidekicks, Vinnie and Tyrone, as well as the Jewish character, Avi. There are two episodes in the middle of the film that bring into relief the difference between the grisly, sadistic British and Russian characters, and the ineffectual Jews and blacks. Both take place in Sol's shop, the first one just after Sol, Vinnie and Tyrone have inadvertently killed Johnny Four Fingers, who has the diamond. Boris arrives and, without batting an eyelid, saws off the arm of the dead Johnny. This is followed by the appearance of Brick Top, who enjoys terrorizing the three men with a monologue on how to get rid of bodies and then threatens them with death. They are scared by this into promising to find the diamond. Then Avi and Doug the Head elicit the help of Bullet Tooth Tony, another sadistic 'Brit'. The difference between the Jews and blacks on the one hand, and the 'Brits' on the other, is exemplified in the second scene in the same location, where Sol, Vinnie and another friend, 'Bad Boy' Lincoln, pretend that the dog has eaten the diamond and Avi tells his sidekick to 'do something terrible'. None of them wants to harm the dog and in the end Vinnie gives up the sought-after diamond rather than see his dog killed. In this way Avi is brought into the circle of stooges who 'don't cut the mustard'. The black men are brought into the orbit of the emasculated schlemiel that has been the domain of the Jew, in contrast to the hypersexed black male of Blaxploitation films, or of Tarantino's films that draw so much from them. Sexual allure, one of the prime signals of masculinity, is absent from all the gangsters, and even the most powerful of the characters is not appealing in any way. Instead, all are envisioned as scumbags - out of control, unable to take command of their circumstances or their responses to them. They are, through the 
filmic devices as well as the plot, denuded of their possible danger as Other and ultimately presented as victims (in direct contrast, say, to The Rise of the Footsoldier - where the violence is traumatic to watch and also shown to have an allure of its own, through the women who are wives and girlfriends in the film). In the lack of sexual allure and the nebbishy quality to the characters, the disdain of the director is palpable: the intention is not for the audience to identify with the characters but to laugh at them without sympathy or humanity. ${ }^{12}$ The violence and corruption is, by the same token, neutered by the jokey, fast editing and musical interventions that deny interior life. The director does not care about the characters: they are just a bit of fun. The other counterpoint is the absence of certain minority ethnicities, notably represented by the Asian who is only silently glimpsed. So, in this film, a particular understanding of identity is envisioned somewhere between the norms and the limits of tolerance. The film does the job of containment, where the minorities which are personified as characters are contained through an emasculated stereotype, while those who are not given characters are the unknowable and are feared Others who cannot even speak: they are the excess. ${ }^{13}$

Wendy Brown describes how 'culture has become a cardinal object of tolerance and intolerance'. ${ }^{14}$ This is particularly so since $9 / 11$, she argues, when the 'clash of cultures' came to be seen to be an explosive force. I would argue that the shift in thinking Brown identifies as taking place after 2001 can also be seen in this film, which was released in 2000. She continues that liberal people consider themselves to have cultures - so that "We" have culture while culture has them (the Other) or we have culture while they (immigrants) are culture', and those that are culture do not have culture and, so the logic goes, are themselves barbaric. In other words, a person of ethnicity (and this is in itself contradictory, as all are ethnic) is defined through 
his/her culture (for instance, a sari-wearing, samosa-eating Indian or a black-hatted Jew with peyes), whereas the normative white person can choose their culture as they are not defined through it. If you are defined through culture you have neither agency nor rationality and therefore are barbaric. In other words, as Brown claims, ' $[\mathrm{t}]$ olerance can work thus as a disciplinary strategy of liberal individualism to the extent that it tacitly schematizes the social order into the tolerated, who are individuated through their deviance from social norms and whose truth is expressed in this individuation, and those doing the tolerating, who are less individuated by these norms ${ }^{15}$ and whose truth is expressed in this individuation. This is where the film's lack of interiority is important in a society that valorizes individualism.

In conclusion, how can Snatch be read usefully to think through what it says about identity politics at the turn of the millennium? I would suggest that this film was part of the wider constituting factors on the brink of a shift, in popular culture, back from agency to essentialism. This was a shift from a universal subject, imagined to arrive at particular beliefs or deliberation, to a subject with beliefs or values by virtue of who he or she is, and who continues to be inscribed by a difference even if the sign of the difference is given up or, as Wendy Brown puts it, situated in a moment when there was a move from 'tolerating opinion and belief to tolerating persons'. ${ }^{16}$ For the liberal subject (arising from Kant's arguments) is autonomous. Culture is exocentric to his or her being and becomes merely a lifestyle choice. For the non-autonomous subject (that is, the characters in Snatch, the Others), culture becomes saturating and authoritative. The non-autonomous subject is not individuated; therefore not rational. In this film the subject as excess - out of control, non-rational and uncontained (while contained within their stereotype, so what is not fulfilled by the stereotype is excess) - is envisioned, and Jewish Avi is part of this 
vision. Although Avi is one of the bosses within the gangster pecking-order, he is on many occasions unable to be commanding, for example when he cannot find the diamond nor Johnny Four Fingers and goes back to New York empty-handed. His inability to be ruthless and his lack of steely determination (in relation to Boris or Bullet Toothed Tony, for example) fulfils Abrams' analysis of on-screen Jews being not quite up to the job and subject to emotionality and sentimentality. There is also a larger point here to be made through the juxtaposition of the ersatz Jews and Avi. Avi has none of the signs of the Jew that the impostors have. He only occasionally wears a kippah, but nonetheless his failings as a Jew stand out. Whatever or whoever he tries to be, he is always the excessive Jew. He may not bear outward signs, but can never really pass. This is the ultimately essentializing message of Snatch - the real, rational, normative subject is the absent, upper-class, English director, which constructs a viewer as also normative, laughing at the buffoons on screen. 


\section{Notes}

${ }^{1}$ If a Lacanian schema were used: the rules and constraints are represented by 'The Symbolic Order'. This relates to the infant's individuation process where he/she chooses language and a symbolized order. This is chosen from the pre-language state that is 'The Real', which has no boundaries, nor coherence. It is the place of excess and the moment when the baby is not aware that he/she is separate from the mother. ${ }^{2}$ Although intertitles introducing protagonists are usual for this genre, in films such as Martin Scorsese's Mean Streets (1973) the descriptors are merely text on the film, whereas in Snatch the overlay of the still adds comic (book) drama.

${ }^{3}$ The scene in Mean Streets where Teresa (Amy Robinson) tries and fails to convince her cousin and lover Charlie (Harvey Keitel) to move to an apartment uptown reveals the central and inextricably bound relationship between community, place and family in this film.

${ }^{4}$ The Essex Boys and The Rise of the Footsoldier both focus on a trajectory of descent into iniquity.

${ }^{5}$ Juliet Steyn, The Jew: Assumptions of Identity, Routledge, 2000, pp. 61-65.

6 'All the superheroes from Clark Kent to Spiderman have double identities', according to Andrea Most in her 'Reimagining the Jew's Body' in You Should See Yourself, ed. Vincent Brook, Rutgers University Press, 2008, p. 19.

${ }^{7}$ See Michael Rogin, Blackface, White Noise: Jewish Immigrants in the Hollywood Melting Pot, University of California Press, London 1996, where the Jew and the black are connected through blackface. 
8 'Blackface is a form of cross-dressing, in which one puts on the insignias of a sex, class, or race that stands in binary opposition to one's own.' Rogin, Blackface, White Noise, p. 30.

${ }^{9}$ According to Du Bois the black subject sees himself through the vision of the wider, non-black society and their racism, which results in a doubling of self and other within the subject.

${ }^{10}$ This is meant here in the Lacanian sense of that which cannot be taken to the Father (The Symbolic). See note 1 above.

${ }^{11}$ Nathan Abrams, The New Jew in Film: Exploring Jewishness and Judaism in Contemporary Cinema, I.B. Taurus, London 2012, p. 98.

12 There is an element of the absurd to the humour also, which adds to the lack of realism - for example the headquarters of 'Turkish' is a filthy, broken caravan with a 'bloke' frying a sausages on a barbecue next to it, in a room with a boxing ring and boxer practising in it, which is at once humourous, abject and eccentric.

${ }^{13}$ This is vividly portrayed in the scene where the Indian workers are glimpsed coming out of the factory and swarming around the crashed car in a Zombie-like silence.

${ }^{14}$ Wendy Brown, Regulating Aversion: Tolerance in the Age of Identity and Empire, Princeton University Press, Princeton 2006, p. 150.

${ }^{15}$ Ibid., p. 44.

${ }^{16}$ Ibid., p. 43. 